\title{
Editorial
}

\section{The Scientific Contributions of Gilbert Gottlieb: An Overview}

\author{
Carolyn Tucker Halpern ${ }^{1}$, Kathryn E. Hood ${ }^{2}$, Richard M. Lerner ${ }^{3}$ \\ ${ }^{1}$ University of North Carolina at Chapel Hill, USA \\ 2 The Pennsylvania State University, USA \\ ${ }^{3}$ Tufts University, USA
}

This special issue of the European Journal of Developmental Science is an expression of appreciation for the life and science of Gilbert Gottlieb, who passed away on July 13, 2006, leaving behind a rich personal and professional legacy. As the contributors to this special issue elaborate, Gottlieb was a major developmentalist and theoretician who, throughout his career, battled against scientific reductionism and advocated for an open, holistic, multi-level systems approach for understanding development. His developmental systems approach grew from decades of his research, which covered the range of emerging and continuing issues. In particular, he challenged the deterministic concept of an innate instinct and offered instead his generative conception of probabilistic epigenesis as a basis for shaping behavioral development as well as evolutionary change.

Professor Gottlieb singly authored five books and edited six books and a serial, while also serving on distinguished editorial boards. His research achievements are presented in 70 published empirical articles (with one in review), and 42 book chapters. The elaboration of Gottlieb's developmental perspective from 1968 to 2004 can be followed through his 21 reviews, which were published in major theoretical journals. His academic career included a long term as a research scientist for the state of North Carolina, followed by a position as Excellence Foundation Professor and head of psychology at the University of North Carolina (Greensboro), president of a professional society, and later as research professor in the psychology department and the Center for Developmental Science at the University of North Carolina (Chapel Hill). His international service includes agency consultations in Prague, Bielefeld, and Moscow. His contributions were acknowledged by national awards and honorary publications, in particular the Distinguished Scientific Contributions to Child Development Award in 1997 from the Society for Research in Child Development.

Gottlieb's contention is that development proceeds in concert with influences from all levels of the organism and the context. "A probabilistic view of epigenesis holds that the sequence and outcomes of development are probabilistically determined by the critical operation of various endogenous and exogenous stimulative events" (Gottlieb, 2004 p. 94). The bidirectional and coactional processes occurring within and across levels of a developmental system were succinctly captured in his 
figurative systems framework (Gottlieb, 1992), shown in Figure 1. In addition to his own empirical research, he avidly searched across disciplines for observations and research findings that exemplified his concepts, i.e., the co-actions in the model depicted in Figure 1.

\section{Bidirectional influences}

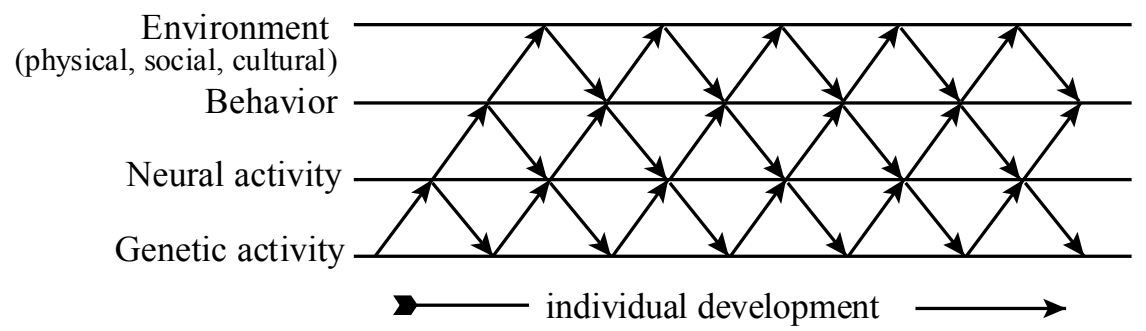

Figure 1. A systems view of psychobiological development. From Individual Development and Evolution: The Genesis of Novel Behavior, by Gilbert Gottlieb, 1992. New York: Oxford University Press. Author's copyright (2002).

We are honored to have had the opportunity to coordinate the assembly of this set of papers from distinguished scholars who have worked with and/or been influenced by Gottlieb's scientific work and mentoring. We requested contributions from scientists who could speak to the significance of several major aspects of his work. Considered together, the papers included here describe the trajectory of Gottlieb's empirical and theoretical work, and aspects of his personal scientific journey.

\section{The Organization of this Issue}

Gottlieb received his $\mathrm{PhD}$ in Clinical and Experimental psychology from Duke University in Durham, N.C. in 1960. His initial empirical work focused on self-stimulation and the context of early experience. Much of this work was done through embryological studies of mallard and wood ducks, conducted at his laboratories at Dorothea Dix Hospital in Raleigh, and in the wooded "natural laboratory" behind his home. The first four papers in this issue highlight the early work. Timothy Johnston describes the long standing nature-nurture (e.g., innateness vs. learning) controversy and its context. He provides a refreshingly clear summary of a large body of work addressing the instinct-learning dichotomy, with a focus on how Gottlieb's experimental work confirmed the role of self-stimulation in shaping behavioral development. Those findings presented an imperative to discard notions of "fixed nature." George Michel further elaborates on Gottlieb's views of bidirectional influences in development with multiple examples of the direct and indirect influences of self-generated experience. David 
Miller collaborated with Gottlieb for seven years in both field and laboratory investigations. He recounts the dedication and discipline required to identify the nonobvious experiential nonlinearities that Gottlieb revealed as part of the multilevel processes that coalesce as developmental outcomes. Celia Moore explains how Gottlieb's earlier embryological work influenced her own perspective. She notes that in addition to his theoretical model of bidirectional developmental systems, Gottlieb's embryological studies provided a methodological model exemplifying the bidirectional approach for developmental psychobiologists.

Three scholars address Gottlieb's theoretical proposal that individual development and behavior are sources of evolutionary change. Gary Greenberg examines Gottlieb's understanding of developmental systems as a model for the relationship between biology and psychology and his thesis that "ontogenetic novelty ...produces evolutionary change" (Greenberg, p.12, this issue), moving the field of comparative psychology toward developmental analysis. Using the vantage point of his own theoretical development, Jean-Louis Gariepy assesses Gottlieb's pivotal contributions to developmental psychology and how Gottlieb further developed the concept of neophenogenesis. Jay Rosenblatt presents a powerful focus on Gottlieb's thinking about the intersections of behavioral development and evolution, and how his thinking matured over the course of Gottlieb's career.

In recent years, Gottlieb focused on debunking the central dogma of molecular biology, which postulates that genetic information flows only in one direction: from DNA to RNA to protein. By contrast, Gottlieb puts genetic activity on a par with other factors in his framework of probabilistic epigenesis, denying the special status of DNA as a "prime mover" in the developmental matrix. Much of his recent theoretical work is dedicated to highlighting the fully coactional developmental systems point of view, especially for biological and behavioral scientists. Gottlieb sometimes expressed skepticism about his (and others') success in this endeavor. Douglas Wahlsten addresses this skepticism in the context of genetic research; he concludes that Gottlieb's assessment was unduly pessimistic. Using examples from their own work on selective attention and perceptional processing, Robert Lickliter and Lorraine Bahrick expound on the utility of comparative animal research in understanding cross-species developmental processes and how such research promotes psychobiological systems meta-theory. Peter Molenaar discusses Gottlieb's contributions to the developmental critique of population-based behavioral genetics. He points to parallel approaches in mathematical biology, which underscore the originality and unique value of Gottlieb's non-linear epigenetic approach to the study of development and change. Jaan Valsiner provides a forward-looking examination of how explication and extension of key concepts from Gottlieb's theory of probabilistic epigenesis might be used to further developmental science. Finally, the paper by Marc Gottlieb describes how his father influenced his own intellectual development and how he has applied his father's key concepts of probabilistic epigenesis to his own clinical and research work in chiropractics. 


\section{Conclusions}

Gottlieb's last empirical paper with Carolyn Halpern and investigators at the Center for Developmental Science at the University of North Carolina at Chapel Hill and the Keck Center for Behavioral Biology at North Carolina State University in Raleigh (Gottlieb et al., in review) is an interdisciplinary effort that demonstrates the coactional contributions of multiple genes and life experiences to complex human phenotypes. Throughout his career Gottlieb used his empirical work to support and further develop his theoretical approach to developmental systems and, with admirable persistence, to convince the scientific community that the classic dualistic, nature-nurture split that focused on single causes of developmental change was a false one.

Also admirable was Gottlieb's interpersonal warmth and wry humor, his kindness and his generosity to junior colleagues and students, as well as his resoluteness, his exceptionally high level of intellectual integrity, his avid pursuit of historical precedents for his ideas, and his excitement about research, including field, laboratory, and library research. His enjoyment of convivial relationships with colleagues was tangible, and his maintenance of long-term relationships with intellectual companions was impressive, including some that were realized through e-mail.

We hope that younger scholars and those who are not familiar with Gilbert Gottlieb's work will find this special issue to be a useful introduction and a source of references to his insightful and original contributions. For scientists and philosophers who are familiar with Gottlieb's work, we hope that this issue serves as a reminder of the innovative facets of his work, and how those fit together to advance the prospects for a truly developmental science.

\section{References}

Gottlieb, G. (1992). Individual development and evolution: The genesis of novel behavior. New York: Oxford University Press.

Gottlieb, G. (2004). Normally occurring environmental and behavioral influences on gene activity: From central dogma to probabilistic epigenesis. In C. Garcia Coll, E.L. Bearer, R.M. Lerner (Eds.) Nature and nurture: The complex interplay of genetic and environmental influences on human development and behavior (pp. 85 - 106). Mahwah, NJ: Lawrence Erlbaum Associates.

Gottlieb, G., Halpern, C.T., Propper, C., Carbone, M.A., Edwards, A., Latendresse, S.J., and Mackay, T.F.C. (in review). Genetic and experiential background to substance use in adolescents: A multiple gene-multiple life experience approach. 
Address for correspondence: Carolyn Tucker Halpern, Carolina Population Center, CB \# 8120, University of North Carolina at Chapel Hill, Chapel Hill, NC 27599-8120, USA;

Email: carolyn_halpern@unc.edu

Carolyn Tucker Halpern is an Associate Professor of Maternal and Child Health. Her research centers on biopsychosocial models of risk taking, sexual development, and romantic partnerships from adolescence into adulthood. She is the Deputy Director of Wave IV of the National Longitudinal Study of Adolescent Health.

Kathryn E. Hood is Associate Professor of Human Development at Pennsylvania State University, USA. She studies social and exploratory behavior in mice from a developmental-genetic perspective. She also studies indicators of resilience in children's interviews in the Carolina Longitudinal Study, together with Hongling Xie.

Richard M. Lerner is the Bergstrom Chair in Applied Developmental Science and the director of the Institute for Applied Research in Youth Development in the Eliot-Pearson Department of Child Development at Tufts University. He is the author or editor of 63 books and more than 450 scholarly articles and chapters. 